Article

\title{
The Humanmade Paradise: Exploring the Perceived Dimensions and Their Associations with Aesthetic Pleasure for Liu Yuan, a Chinese Classical Garden
}

\author{
Xin Li ${ }^{1} \oplus$, Bing Xia ${ }^{2, *}$, Anne Lusk ${ }^{3}$, Xing Liu ${ }^{4}$ and Ning Lu ${ }^{5}$ \\ 1 School of Urban Design, Wuhan University, Wuhan 430072, China; li-xin@whu.edu.cn \\ 2 College of Civil Engineering and Architecture, Zhejiang University, Hangzhou 310058, China \\ 3 Harvard T. H. Chan School of Public Health, Department of Nutrition, Boston, MA 02109, USA; \\ annelusk@hsph.harvard.edu \\ 4 Department of Architecture, Fine Arts Academy, South-Central University for Nationalities, \\ Wuhan 430074, China; liu.xing.arch@mail.scuec.edu.cn \\ 5 College of Architecture and Urban Planning, Qingdao University of Technology, Qingdao 266033, China; \\ lu_ncl@163.com \\ * Correspondence: 0016217@zju.edu.cn
}

Received: 1 February 2019; Accepted: 26 February 2019; Published: 4 March 2019

check for updates

\begin{abstract}
Investigating how people perceive Chinese Classical Gardens (CCGs) and their appeal are important issues of landscape studies. By considering the Liu-Yuan Garden, we developed a measurement instrument to investigate the perceived dimensions of landscape appreciation. Based on literature review, the descriptive items to measure how people perceived Liu-Yuan Garden were developed. Then, the explorative factor analysis and confirmatory factor analysis were employed, and six dimensions were extracted and validated including "Adoration", "Nostalgia", "Liveliness", "Exquisiteness", "Hedonic Value", and "Placeness". Finally, the Ordinary Linear Regression method was employed to estimate how the aesthetic appreciation is influenced by these perceived dimensions. The result revealed that four of these dimensions were significantly correlated with aesthetic pleasure. The influences of these perceived dimensions on aesthetic pleasure were measured and compared. The results indicated that "Placeness" provided the most important influence on aesthetic pleasure, whereas "Liveliness" was the least influential of the four related dimensions.
\end{abstract}

Keywords: landscape; aesthetic pleasure; perceived dimension; Chinese Classical Gardens; regression model; Liu-Yuan

\section{Introduction}

People are affected by the aesthetics of nature, landscapes, and architecture [1-4]. Different landscape characteristics influence people's attitudes, and eventually translate to the landscape experience and aesthetic pleasure [5]. As a distinctive branch of the world's landscape family and excellent carriers of East Asian cultures, Chinese Classical Gardens (CCGs) encapsulate advantages of sustainability, ecological value, urban function, pleasure, and healthcare [6]. Among these benefits, the landscape aesthetics of CCGs have been extensively recognized as important attributes to evaluate their overall quality [7], although empirical studies on this issue with quantitative methods are still in a lack.

Aesthetic pleasure involves comprehensive judgments in a complex process that includes perception, interpretation, and appraisal [8]. It was suggested to assess landscape aesthetics from a formal perspective, which was regarded as the sensate appreciation of the physical attributes in the visual world (e.g., volume, order, and richness) [9-11]. For landscape studies, there has been persistent 
accentuation of investigating the visual properties when assessing the aesthetic value of a landscape work [12-14]. For instance, plants are often regarded as one of the most important components that influence people's perception of landscapes among these visual elements $[15,16]$. The scenic beauty estimation methods that rely largely on the photos prepared by researchers were well used to evaluate aesthetic values $[17,18]$. Nine visual concepts, i.e., naturalness, complexity, coherence, and historicity, were identified trying to characterize landscape aesthetics [19]. However, such framework was developed mainly for the landscape assessment rather than for analyzing correlations between these visual concepts and landscape aesthetics. To our best knowledge, attempts of validation with such framework have been scarcely reported. The weights of different visual concepts contributing to landscape pleasure have been neither clarified yet.

Moreover, although previous studies on CCGs have been explored on space qualities [20,21], configurations [22,23], and visual aspects [24-26], whereas similar empirical studies integrating people's perceptive attitudes have not been fully addressed in the literature and seldom applied to a CCG case. During the last two decades, Western countries gradually reached a consensus that landscape could be defined as "an area, as perceived by people, whose character is the result of the action and interaction of natural and/or human factors" [27], highlighting the important role of perceptive attributes to shape a landscape with specific aesthetic characters [28]. Therefore, more attempts are needed to incorporate broader concepts of emotion or experience to address relevant humanity aspects in landscape appreciation $[29,30]$. Accordingly, whether there are undetected human perceptions embodied in landscape aesthetics, if so, how aesthetic pleasure is associated with them, and how CCGs can be evaluated in terms of these perceived dimensions, are interesting but unsolved issues that need to be explored in this research.

Empirically, we hypothesize that aesthetic pleasure is a multidimensional concept that simultaneously embodies a series of potential perceptions. We also hypothesize that these perceived dimensions in turn affect aesthetic pleasure (Figure 1). To fill in these knowledge gaps, this paper aimed to deepen the psychological understanding of what perceived dimensions emerge when tourists appreciate CCGs, and in turn, how these dimensions affect aesthetic pleasure. In previous studies, component-based analyses have been used to associate landscape attributes with aesthetic preference quantitatively but occasionally yielded controversial arguments [31]. However, our study combined the factor analysis with multiple-regression can overcome such problem [31].

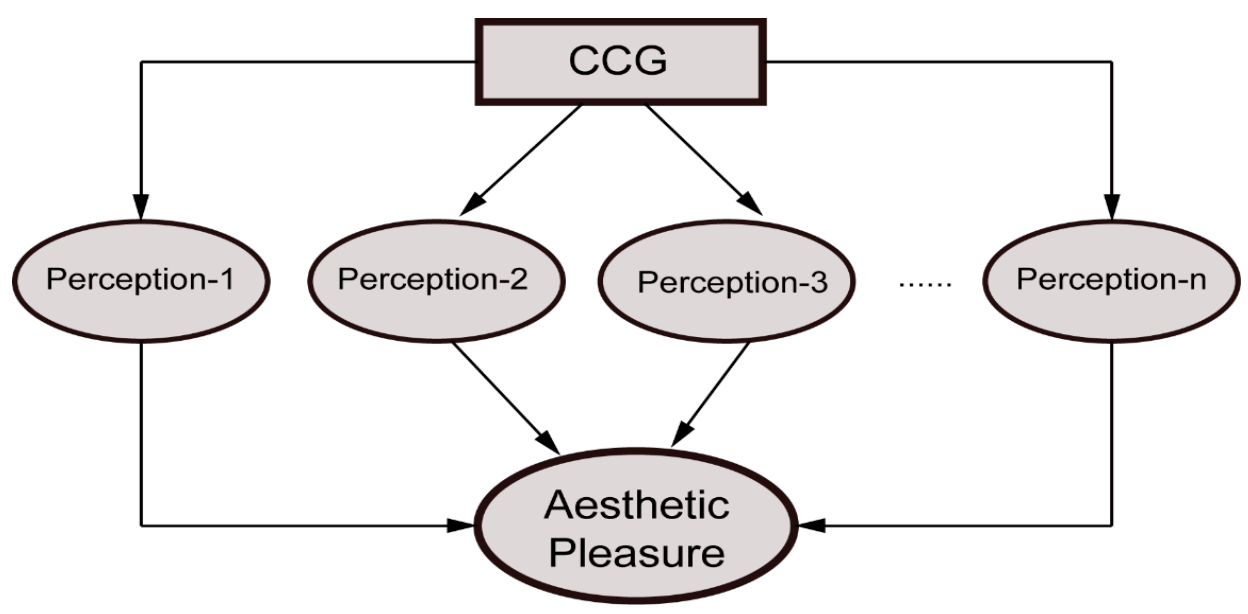

Figure 1. The hypothetical framework. CCG: Chinese Classical Gardens.

The rest of this paper is organized as follows: Section 2 provides a brief literature review. Section 3 introduces the background of the selected case, general methods involved in this study, and the analysis procedures. Section 4 develops the measurement instruments to generate the explorative dimensions. Section 5 presents a series of interrelated and consequential analyses to validate the 
proposed dimensions. Section 6 establishes regression models to align aesthetic pleasure with the proposed dimensions. Section 7 summarizes the main findings of this paper with discussions and implications. Section 8 concludes the article with some possible limitations.

\section{Literature review}

\subsection{Aesthetic Pleasure}

Aesthetics has been widely used to generalize the concept of beauty across various academic disciplines [32]. Aesthetic pleasure is an immediate and essential emotion that derives from appreciating an object for its own sake with a "disinterested" or "distanced" manner in that no utilitarian preference, as such, is involved [33]. It does not mean that perceptive motives are completely isolated from aesthetic experience; rather it emphasizes that the functionality of an object and the corresponding fulfillment of certain usefulness is not essentially necessary for aesthetic pleasure [34]. According to this definition, it is easy to understand why aesthetic pleasing emerges when people watch a painting exhibition, listen to a concert, view natural sceneries, and experience a landscape. Although aesthetic pleasure is often aroused when people enjoy art works, such perceptive experience could be regarded as a kind of appreciation to anything with aesthetic values [34].

The process of aesthetic appreciation involves different senses (e.g., visualizing, touching, hearing, and other related mental activities) and triggers a series of complex perceptual emotions [35]. In line with Lang's viewpoint [10], aesthetic pleasure is a percept-centred process that could be realized via two different modes: formal aesthetics and symbolic aesthetics. In the field of landscape, some literatures have emphasized that delightful emotions could easily derive from the "visual quality" of form, i.e., visual properties of a viewed landscape [13,36]. The mode advocating the visual idea of landscape is similar with what Berleant called "the panoramic landscape" [37]. In terms of formal aesthetics, the measurable structural/geometric properties of the forms (e.g., proportion, scale, repetition, and unity) are regarded as important factors to provide viewers with affective feelings during the perceptual process. As components of formal aesthetics, the concepts of harmony, complexity, hierarchy, and configuration are regarded to be associated with aesthetic pleasure $[10,38]$. In order to reveal some landscape design principles in CCGs, our study employed the empirical method to mainly investigate the formal aesthetics of CCGs with the combination of people's aesthetic perceptions.

\subsection{Perceived Dimensions in Landscape Aesthetics}

It was suggested that aesthetic pleasure is not only confined to the physical gratification [37], but also applies to perceptive reactions. It was also indicated that aesthetic experiences could be evoked by different human perceptions of the environment [36]. Different emotional bonds and landscape experiences provide people with various perceived dimensions to understand a meaningful natural or built environment that incorporates values, ideas, and beliefs, conferring the physical space with a sense of place $[5,39]$. Specifically, some have suggested utilizing descriptive indicators to identify people's underlying perceptions [40]. Therefore, it is necessary to improve the understanding about how people perceive and experience landscape via the apprehension of various sense qualities.

In prior studies, various descriptive items have been employed to associate with aesthetic pleasure according to certain purposes in different fields. For instance, descriptive items like, "beautiful", "attractive", "fascinating", and "delightful", are commonly used to explore the aesthetic value of art works [41]. In other design field, items like, "pleasing", "original", "innovative", "sophisticated", and "symmetrical", are more commonly involved for aesthetic measurement [42]. In the field of human-computer interaction (HCI), aesthetic pleasure is often related with "hedonic value" and "goodness" [43]. These prior studies were helpful to provide insights for better understanding the underlying psychological and cognitive structure of aesthetic appreciation. However, there have been few evidences showing that all these scales are compatible when they are transplanted into the measurement of aesthetic qualities in landscape since the interaction between perceivers and landscape 
are more intensive and complicated [28]. Therefore, it is necessary to explore underlying perceptions out of aesthetic pleasure when people appreciate CCSs, and to reveal the corresponding association between the two.

For landscape studies, some have identified nine dimensions to evaluate landscape characteristics among which four dimensions are mainly focused in our study [44], i.e., naturalness, complexity, coherence, and historicity. These dimensions were summarized from existing landscape literatures and considered critical to interpret various landscape preferences. Some other scholars followed this framework and further elaborated the description of these dimensions from abstract concepts to measurable indicators [19]. Among these dimensions, naturalness describes the perception of people's intimacy with natural elements (e.g., water, plants, and mountains.) and related lively processes, and living with naturalness is regarded supportive to the restorative environment that is beneficial both for physical relaxation and mental health [45]. Complexity conceptualizes the richness of the landscape either because of the diverse landscape features or the mixed patterns. Coherence is defined as the overall unity of landscape visual quality. The importance of historicity has also been emphasized in the landscape literature, describing the appreciation of historical continuity. These concepts were carefully considered when we prepared the measuring instruments in this study.

\section{Description of the Case Study}

Located in the northwest quarter of Suzhou City in Jiangsu Province, China, the Liu-Yuan Garden was initially built during the Ming Dynasty (approximately 1593 AD) as a large private residence and was expanded and restored during the Qing Dynasty. At present, the Liu-Yuan Garden covers an area of approximately 2.33 ha and is open to the public as a garden museum. It is one of the most important representatives of CCGs, and it has been listed as a national cultural relic of China since 1961 and as a UNESCO World Heritage Site since 1997. We selected the Liu-Yuan Garden as an example to explore what perceived dimensions might emerge and whether these psychological perceptions would shed on aesthetic pleasure.

The layout of Liu-Yuan Garden can be divided into five independent zones with thematic characteristics: the southern zone connecting to an intricate entrance gallery; the central zone featuring an open space and waterscape; the eastern zone serving as living courtyards, the northern zone featuring rockery works and caves; and the western zone, which is dedicated to an idyllic lifestyle. In addition, the spaces interact and penetrate across different zones (Figure 2). Furthermore, walls further subdivide these five parts into many subsidiary gardens and courtyards. In this garden, buildings only account for $15 \%$ of the total area, whereas other landscape elements such as buildings, vegetation, landform, rockery works and caves, waters, and so on comprise its majority and are systematically organized along well-designed scenery locations to enhance visual effects and the space experience via transition, convergence, and contrast. 


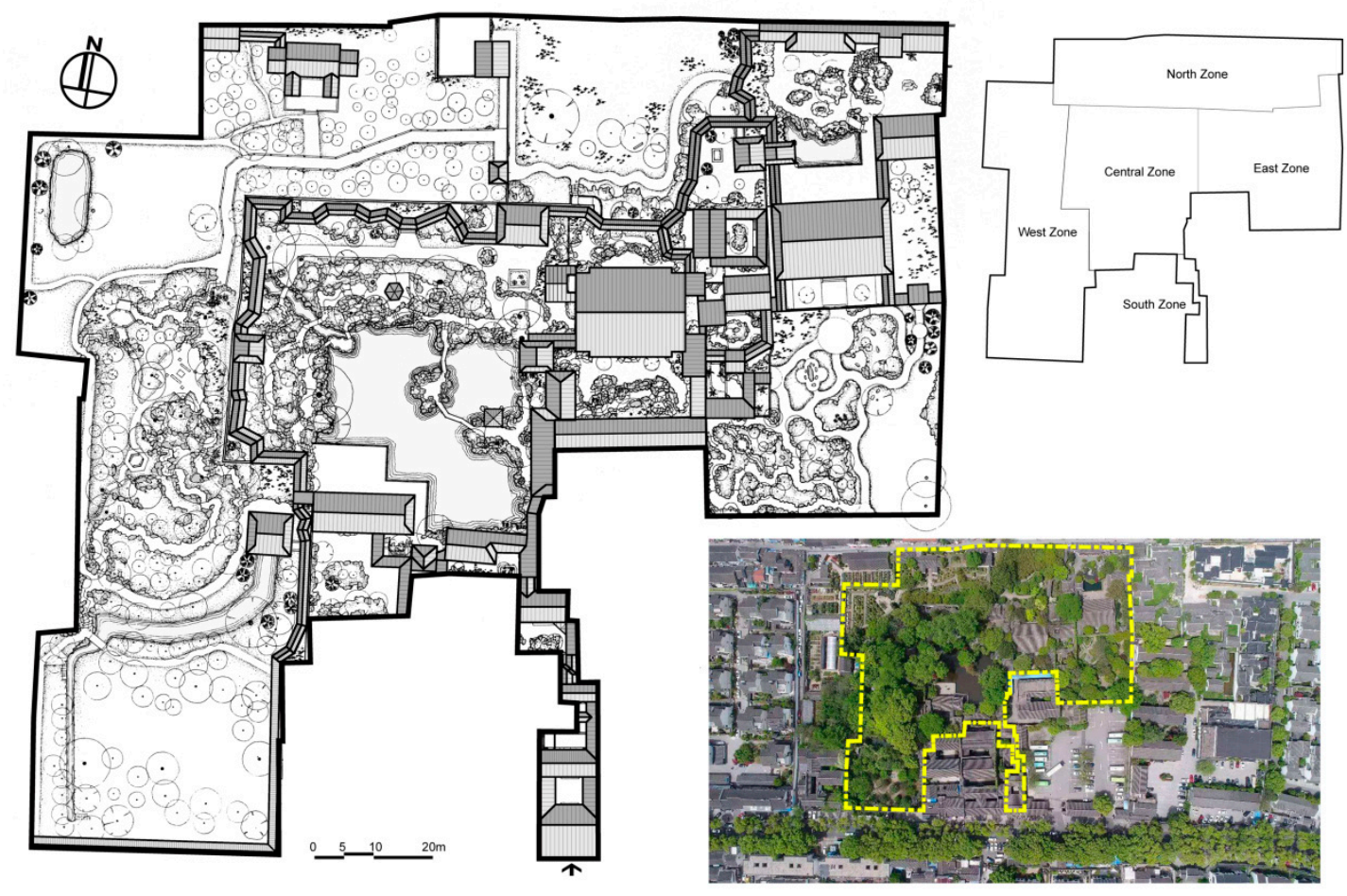

Figure 2. The layout of the Liu-Yuan Garden in Suzhou, China.

\section{Methods and Materials}

This research began with the development of descriptive items to measure how people think about the perceived dimensions of Liu-Yuan Garden. Then, the explorative factor analysis (EFA) was employed to identify the potential dimensions. After, the confirmatory factor analysis (CFA) was conducted for dimension validation. Finally, the Ordinary Linear Regression (OLR) was employed to validate how and to what extent the aesthetic appreciation is influenced by different perceived dimensions.

\subsection{Instruments and Descriptive Items}

We attempted to induce the natural reactions that underlie people's perceptions of the CCG in an exploratory manner. For this purpose, thirteen experts from relevant fields (including five landscape architects, three gardeners, three civil engineers, and two cognitive scientists) and twenty representative architectural students were invited to a seminar where they developed an list of descriptive items that might apply to their perceptions of the CCG using the following process. (1) Beforehand, the research team prepared a pool of optional descriptive adjectives or phrases that identified the general aesthetic values of the CCG and disseminated them to the jury for consideration. (2) The stimuli of the selected case (a video and photos) were presented to the jury to create a straightforward and intuitive impression of the CCG. The video was recorded along the conventional routine of the garden and forty-five photos were taken within major scenery spots to address the garden features. (3) Each jury member was allowed to provide additional descriptive items if necessary. (4) Suitable items were selected within the larger pool and those duplicates and conflicting items were filtered. The selected items met the criteria of easy understanding, common usage, and briefly capturing the features of the garden, excluding jargon and confusing words. Items directly related to the dimension of aesthetic pleasure were also screened because they were considered as comprising the dimension of aesthetic pleasure in the next step, and their early involvement might create an unexpected bias with regard to the explorative analysis. All of the descriptive items (Table 1) were measured using a structured questionnaire survey. A pretest was performed to eliminate terminology and ambiguous expressions, ensuring 
easy readability for the respondents. A seven-point Likert scale ranging from "strongly disagree" to "strongly agree" was used in the survey.

\subsection{Data Collection}

The data collection was conducted in two separate phases. For the first phase, 177 architectural students participated in this experiment as respondents. For the raw data, 12 completed surveys were removed because of obvious errors on their answer sheets. Eventually, 165 completed surveys were selected for the final report, with effective entries of 76 males $(46.1 \%)$ and 89 females $(53.9 \%)$. The questionnaire survey was conducted across several batches in a supervised multimedia classroom. The participants watched the same stimuli that were presented during the item-generation session. Afterwards, they completed a questionnaire that contained the initial list of descriptive items based on their perceptions of the garden. The participants made complementary comments after they finished the survey. Data entry was checked to ensure the absence of outliers or missing values within the measured variables. The approximate normality of each continuous variable was also examined beforehand to meet the acceptable criteria of skewness (values between -1 and +1 ) and kurtosis (values between -5 and +5 ) [46].

For the second phase, the data collection was conducted along with a joint summer school workshop with other six universities of China. In this workshop, 153 students from different disciplines were summoned to participate in a field trip to Liu-Yuan Garden. These participants were asked to finish a questionnaire survey after they visited the garden. Because some previous studies indicated that prior experience to a specific place might generate potential bias to travelers' attitudes [47], we decided to exclude 28 participants from the final entries to alleviate such influence because they had visited this garden within the recent two years. Finally, we obtained 125 valid entries for further analysis. Among the valid observations, there were 69 males (54.3\%) and 58 females (45.7\%). These data entries were checked to exclude outliers or missing values from the measured variables. The skewness (from -1 to 1 ) and kurtosis (from -5 to 5 ) of each variable met the acceptable criteria of approximate normality (Table 2). The following procedures were required: (1) Participants were provided with a map of this garden beforehand and encouraged to visit its major scenery spots. (2) They were also encouraged to take photos when visiting the garden and make remarks on the map. (3) After the field trip, they completed the questionnaire independently based on their experience in and perceptions of the garden, avoiding mutual interference. (4) After this rating, the participants were also able to make complementary comments.

\subsection{Extracting the Potential Perceived Dimensions}

To refine the initial pool of descriptive items, we conducted EFA in which correlated items can be integrated into an independent dimension. The EFA was employed with the data of the first phase, and followed a series of consequential procedures and analytical decisions [48,49]. According to Hair's recommendation [46], the loadings of each item should be at least 0.5 , and the cut-off loading was suggested over 0.60 , whereas items with cross-loadings over 0.5 should be rejected as a means of item juxtaposition among several dimensions. Moreover, the Kaiser-Meyer-Olkin (KMO) index should be close to 0.6 or higher [46]. The results indicated that the KMO index was higher than 0.812 , meeting the required criteria for further analysis. Through a Varimax rotation, six dimensions with eigenvalues greater than 1.00 were extracted (Table 3), explaining approximately $62.5 \%$ of the item variance. Eventually, six dimensions were extracted (Table 1). In summary, the dimension with the items that stressed spiritual admiration toward the garden (e.g., "sacred", "magnificent", "grand", and "transcendent") was termed "Adoration" (AD); The dimension with the items that expressed characteristics of the past (e.g., "reminiscent", "old", and "antique") was termed "Nostalgia" (NOS); The dimension with the items that described the organic features of the garden (e.g., "lively", "picturesque", and "vivid") was termed "Liveliness" (LV); The dimension with the items that focused on exquisite workmanship and design qualities (e.g., "informative details" and "elaborate") was termed 
"Exquisiteness" (EX); The dimension with the items that depicted respondents' physical and mental enjoyment (e.g., "comfortable", "leisurely", and "entertaining") was termed "Hedonic Value" (HD); The dimension with the items that encompassed an emotional and symbolic attachment to the garden (e.g., "sense of attachment", "sense of belonging", and "sheltered") was termed "Placeness" (PL).

Table 1. The initial list of descriptive items and loadings of explorative factor analysis (EFA).

\begin{tabular}{|c|c|c|c|c|c|c|}
\hline \multirow{2}{*}{ Descriptive Items } & \multicolumn{6}{|c|}{ Loadings } \\
\hline & C-1 & $\mathrm{C}-2$ & $\mathrm{C}-3$ & C-4 & C-5 & C-6 \\
\hline Organic & 0.832 & -0.093 & 0.136 & 0.035 & 0.185 & -0.079 \\
\hline Picturesque & 0.831 & -0.167 & 0.188 & 0.042 & 0.212 & -0.081 \\
\hline Lively & 0.806 & -0.042 & -0.031 & 0.020 & 0.047 & 0.084 \\
\hline Vivid & 0.752 & -0.009 & 0.214 & 0.036 & 0.132 & -0.078 \\
\hline Whimsical & 0.594 & -0.321 & 0.134 & -0.098 & 0.239 & 0.041 \\
\hline Transcendent & -0.089 & 0.824 & -0.104 & 0.210 & 0.007 & 0.005 \\
\hline Grand & -0.131 & 0.818 & -0.225 & 0.222 & -0.050 & 0.088 \\
\hline Dignified & -0.053 & 0.776 & 0.007 & 0.204 & -0.081 & 0.112 \\
\hline Magnificent & -0.082 & 0.746 & -0.185 & 0.310 & -0.276 & 0.030 \\
\hline Mysterious & -0.137 & 0.489 & 0.451 & 0.083 & -0.051 & -0.054 \\
\hline Sacred & -0.136 & 0.395 & 0.211 & -0.235 & -0.084 & -0.005 \\
\hline Exquisite & 0.131 & -0.004 & 0.811 & -0.015 & 0.055 & -0.086 \\
\hline Elaborate & 0.175 & -0.213 & 0.763 & 0.066 & 0.224 & -0.059 \\
\hline Informative details & 0.195 & 0.026 & 0.754 & 0.094 & 0.188 & 0.022 \\
\hline Complex & 0.517 & -0.046 & 0.597 & -0.007 & 0.177 & -0.052 \\
\hline Imaginative & 0.058 & -0.055 & 0.538 & 0.325 & 0.280 & -0.037 \\
\hline Antique & -0.009 & 0.330 & 0.136 & 0.808 & -0.051 & -0.110 \\
\hline Sense of history & 0.005 & 0.318 & -0.005 & 0.796 & 0.088 & 0.028 \\
\hline Old & 0.059 & -0.089 & 0.121 & 0.775 & -0.163 & 0.009 \\
\hline Reminiscent & 0.038 & 0.099 & -0.004 & 0.737 & 0.114 & 0.088 \\
\hline Tranquil & -0.051 & 0.266 & 0.081 & 0.445 & -0.021 & -0.127 \\
\hline Comfortable & 0.324 & -0.090 & 0.156 & 0.145 & 0.778 & -0.020 \\
\hline Entertaining & 0.330 & 0.048 & -0.006 & 0.033 & 0.760 & -0.107 \\
\hline Leisurely & 0.230 & -0.147 & 0.249 & 0.020 & 0.752 & -0.041 \\
\hline Wandering & 0.280 & -0.132 & 0.375 & -0.025 & 0.548 & 0.097 \\
\hline Satisfactory & -0.082 & -0.117 & 0.148 & -0.136 & 0.512 & 0.148 \\
\hline Sense of belonging & -0.022 & 0.098 & -0.047 & 0.006 & 0.042 & 0.860 \\
\hline Sheltered & -0.018 & -0.034 & -0.073 & -0.054 & -0.025 & 0.858 \\
\hline Sense of attachment & 0.021 & -0.084 & -0.116 & -0.046 & 0.059 & 0.774 \\
\hline Secluded & 0.013 & 0.252 & -0.002 & -0.184 & 0.218 & 0.536 \\
\hline Intimate & -0.088 & 0.014 & 0.082 & 0.173 & -0.177 & 0.536 \\
\hline
\end{tabular}

Note: Items are removed from the list if they do not meet the required criteria. The bold numbers are those that confirm the factor loading criteria.

Table 2. The confirmatory factor analysis (CFA) statistics and normal distribution tests. AD: Adoration; NOS: Nostalgia; LV: Liveliness; EX: Exquisiteness; HD: Hedonic Value; PL: Placeness.

\begin{tabular}{ccccc}
\hline Items & Mean & Std. Deviation & Skewness & Kurtosis \\
\hline AD1 & 2.95 & 1.17 & 0.55 & 0.09 \\
AD2 & 3.24 & 1.28 & 0.25 & -0.54 \\
AD3 & 3.46 & 1.34 & 0.33 & -0.48 \\
AD4 & 4.08 & 1.50 & -0.19 & -0.96 \\
NOS1 & 5.82 & 1.02 & -0.77 & 0.26 \\
NOS2 & 5.05 & 1.37 & -0.56 & 0.10 \\
NOS3 & 5.88 & 0.83 & -0.28 & -0.15 \\
NOS4 & 5.73 & 1.01 & -0.80 & 1.00 \\
LV1 & 6.20 & 0.67 & -0.41 & -0.06 \\
LV2 & 6.07 & 0.83 & -0.65 & -0.07 \\
LV3 & 6.11 & 0.84 & -0.87 & 0.43 \\
EX1 & 6.11 & 0.80 & -0.87 & 1.18 \\
\hline
\end{tabular}


Table 2. Cont.

\begin{tabular}{ccccc}
\hline Items & Mean & Std. Deviation & Skewness & Kurtosis \\
\hline EX2 & 6.20 & 0.71 & -0.59 & 0.19 \\
EX3 & 5.87 & 0.99 & -0.59 & -0.44 \\
HD1 & 6.12 & 0.83 & -0.65 & -0.23 \\
HD2 & 6.06 & 0.94 & -0.64 & -0.57 \\
HD3 & 5.83 & 0.99 & -0.41 & -0.66 \\
PL1 & 5.20 & 1.30 & -0.15 & -0.93 \\
PL2 & 4.58 & 1.34 & -0.01 & -0.74 \\
PL3 & 5.09 & 1.27 & -0.35 & -0.68 \\
\hline
\end{tabular}

Table 3. The eigenvalues of the explorative dimensions.

\begin{tabular}{ccccccc}
\hline & \multicolumn{3}{c}{ Initial } & \multicolumn{3}{c}{ Rotated } \\
\cline { 2 - 7 } Components & Eigenvalue & $\begin{array}{l}\text { Individual } \\
\text { Percentage }\end{array}$ & $\begin{array}{l}\text { Cumulative } \\
\text { Percentage }\end{array}$ & Eigenvalue & $\begin{array}{c}\text { Individual } \\
\text { Percentage }\end{array}$ & $\begin{array}{c}\text { Cumulative } \\
\text { Percentage }\end{array}$ \\
\cline { 2 - 7 } Comp-1 & 6.795 & 21.919 & 21.919 & 3.749 & 12.093 & 12.093 \\
Comp-2 & 4.455 & 14.371 & 36.291 & 3.539 & 11.416 & 23.509 \\
Comp-3 & 2.851 & 9.195 & 45.486 & 3.233 & 10.428 & 33.938 \\
Comp-4 & 2.037 & 6.569 & 52.056 & 3.163 & 10.204 & 44.142 \\
Comp-5 & 1.740 & 5.614 & 57.669 & 2.895 & 9.337 & 53.479 \\
Comp-6 & 1.499 & 4.837 & 62.506 & 2.798 & 9.027 & 62.506 \\
\hline
\end{tabular}

\subsection{Confirming the Perceived Dimensions}

Ten items that failed to meet the criteria in EFA were removed from the initial list; therefore we kept 20 descriptive items for the second phase survey to ensure that they focused on the relevant the point and could be understood easily. Additionally, the dimension of aesthetic pleasure was defined by adopting three descriptive items (e.g., "It's pleasing to see this garden", "This garden is beautiful", and "I like this garden") [50]. These items were added to the revised questionnaire, and a seven-point Likert scale, ranging from "strongly disagree" to "strongly agree", was used.

To validate the six proposed dimensions, the CFA was employed to validate the structure of the six proposed dimensions (Table 3). The result of the CFA indicated that all six dimensions were well identified in the correct order based on the criteria of eigenvalues greater than $1.0 ; 75.35 \%$ of the total variance was extracted. The KMO index and Bartlett's index also met the required criteria $(\mathrm{KMO}=0.756, p<0.001)$, demonstrating the validation of the proposed dimensions of the aesthetic values of CCGs.

This result confirmed the six proposed dimensions with well-accepted reliability and validity according to Hair's recommendation [46]. Regarding dimension reliability, the Cronbach's $\alpha$ of each dimension met the criteria of greater than 0.8 . The internal consistency of all of the items within each dimension was also measured using composite reliability, and the result met the suggested criteria of between 0.853 and 0.909 . Regarding the convergent validity, only the loadings exceeding 0.6 are presented (Table 4). The average variance extracted (AVE) of each dimension exceeded 0.60 as suggested. The discriminant validity was also tested to examine whether individual dimensions could be adequately distinguished from each other. The result was accepted based on the suggested criteria [51], given that the AVE square root of each dimension (in bold along the principal diagonal in Table 5) is greater than the corresponding correlations of other dimensions. 
Table 4. Results of the reliability of the proposed dimensions.

\begin{tabular}{|c|c|c|c|c|c|c|c|c|c|c|c|}
\hline & \multirow{2}{*}{ Items } & \multicolumn{7}{|c|}{ Loadings } & \multicolumn{3}{|c|}{ Reliability } \\
\hline & & C-1 & C-2 & C-3 & C-4 & $C-5$ & C-6 & SMC & Conbach's $\alpha$ & C.R. & AVE \\
\hline \multirow{4}{*}{$\mathrm{AD}$} & AD1 & 0.890 & - & - & - & - & - & 0.792 & \multirow{4}{*}{0.862} & \multirow{4}{*}{0.909} & \multirow{4}{*}{0.714} \\
\hline & AD2 & 0.899 & - & - & - & - & - & 0.808 & & & \\
\hline & AD3 & 0.836 & - & - & - & - & - & 0.699 & & & \\
\hline & AD4 & 0.747 & - & - & - & - & - & 0.558 & & & \\
\hline \multirow{4}{*}{ NOS } & NOS1 & - & 0.780 & - & - & - & - & 0.608 & \multirow{4}{*}{0.802} & \multirow{4}{*}{0.870} & \multirow{4}{*}{0.627} \\
\hline & NOS2 & - & 0.811 & - & - & - & - & 0.658 & & & \\
\hline & NOS3 & - & 0.827 & - & - & - & - & 0.684 & & & \\
\hline & NOS4 & - & 0.746 & - & - & - & - & 0.557 & & & \\
\hline \multirow{3}{*}{ LV } & LV1 & - & - & 0.749 & - & - & - & 0.561 & \multirow{3}{*}{0.831} & \multirow{3}{*}{0.853} & \multirow{3}{*}{0.660} \\
\hline & LV2 & - & - & 0.839 & - & - & - & 0.704 & & & \\
\hline & LV3 & - & - & 0.846 & - & - & - & 0.716 & & & \\
\hline \multirow{3}{*}{ EX } & EX1 & - & - & - & 0.859 & - & - & 0.738 & \multirow{3}{*}{0.804} & \multirow{3}{*}{0.865} & \multirow{3}{*}{0.681} \\
\hline & EX2 & - & - & - & 0.815 & - & - & 0.664 & & & \\
\hline & EX3 & - & - & - & 0.800 & - & - & 0.640 & & & \\
\hline \multirow{3}{*}{ HD } & HD1 & - & - & - & - & 0.837 & - & 0.701 & \multirow{3}{*}{0.876} & \multirow{3}{*}{0.882} & \multirow{3}{*}{0.714} \\
\hline & HD2 & - & - & - & - & 0.894 & - & 0.799 & & & \\
\hline & HD3 & - & - & - & - & 0.801 & - & 0.642 & & & \\
\hline \multirow{3}{*}{ PL } & PL1 & - & - & - & - & - & 0.828 & 0.686 & \multirow{3}{*}{0.844} & \multirow{3}{*}{0.875} & \multirow{3}{*}{0.701} \\
\hline & PL2 & - & - & - & - & - & 0.870 & 0.757 & & & \\
\hline & PL3 & - & - & - & - & - & 0.812 & 0.659 & & & \\
\hline
\end{tabular}

Table 5. Results of the discriminant validity of the proposed dimensions.

\begin{tabular}{ccccccccc}
\hline Dimensions & Mean & AVE & AD & NOS & LV & EX & HD & PL \\
\hline AD & 3.43 & 0.714 & $\mathbf{0 . 8 4 5}$ & & & & & \\
NOS & 5.62 & 0.627 & $0.176^{*}$ & $\mathbf{0 . 7 9 2}$ & & & & \\
LV & 6.06 & 0.660 & -0.071 & $0.235^{* *}$ & $\mathbf{0 . 8 1 2}$ & & & \\
EX & 6.0 & 0.681 & 0.078 & $0.197^{*}$ & $0.188^{*}$ & $\mathbf{0 . 8 2 5}$ & & \\
HD & 5.90 & 0.714 & -0.023 & 0.080 & $0.451^{* *}$ & $0.331^{* *}$ & $\mathbf{0 . 8 4 5}$ & \\
PL & 4.96 & 0.701 & 0.083 & 0.117 & $0.374^{* *}$ & $0.189^{*}$ & $0.416^{* *}$ & $\mathbf{0 . 8 3 7}$ \\
\hline
\end{tabular}

Note: The diagonal numbers in bold represent the square roots of the AVE; off-diagonal elements are the correlation estimates; $\left({ }^{*} \mathrm{R}<0.3,{ }^{* *} 0.3<\mathrm{R}<0.5\right.$ and robust standard errors).

\section{Result}

\subsection{Descriptive Statistics}

Each dimension was quantified by calculating the mean of all items within. The six dimensions and the aesthetic pleasure approximated a normal distribution (Table 2). The result showed that the medians of the six proposed dimensions were close to their means $\left(\mathrm{Mean}_{\mathrm{AD}}=3.43, \operatorname{Mean}_{\mathrm{NOS}}=5.62\right.$, $\operatorname{Mean}_{\mathrm{LV}}=6.06$, Mean $_{\mathrm{HD}}=5.90, \mathrm{Mean}_{\mathrm{EX}}=6.00$, Mean $\left.\mathrm{PL}=4.96\right)$, and most of the scores were above 4.0, except for $\mathrm{AD}$, indicating that respondents generally present positive attitudes toward Liu-Yuan Garden (Figure 3). The median and mean of LV were both above 6.0, both ranked as the highest among all six dimensions. As a whole, the interquartile range of LV was the smallest, and first quartile of the LV scores was higher (above 4.0) than those of the other five dimensions. This finding is consistent with the characteristic of Liu-Yuan Garden as a place with heavy greenery and vegetation, and it reflects that it is easy for most of respondents to agree on this dimension. The median and mean of HD (approximately 6.0) were both the second highest values among all six dimensions. The first quartile of HD was above 4.0. A similar situation applied to the dimension of EX. Again, this finding confirms the high quality of the lingering experience of Liu-Yuan Garden. Although the PL scores of the respondents were relatively lower and dispersed, their overall attitude toward this dimension remained positive (its median and mean were approximately 5.0 ), and only the bottom $25 \%$ of the scores were below 4.0. By contrast, the median and mean of AD were clearly below 4.0, and only 
the top $25 \%$ of the scores were above 4.0 . As a whole, the AD scores were the lowest among the six dimensions, presenting respondents' overall disagreement with regard to this dimension.

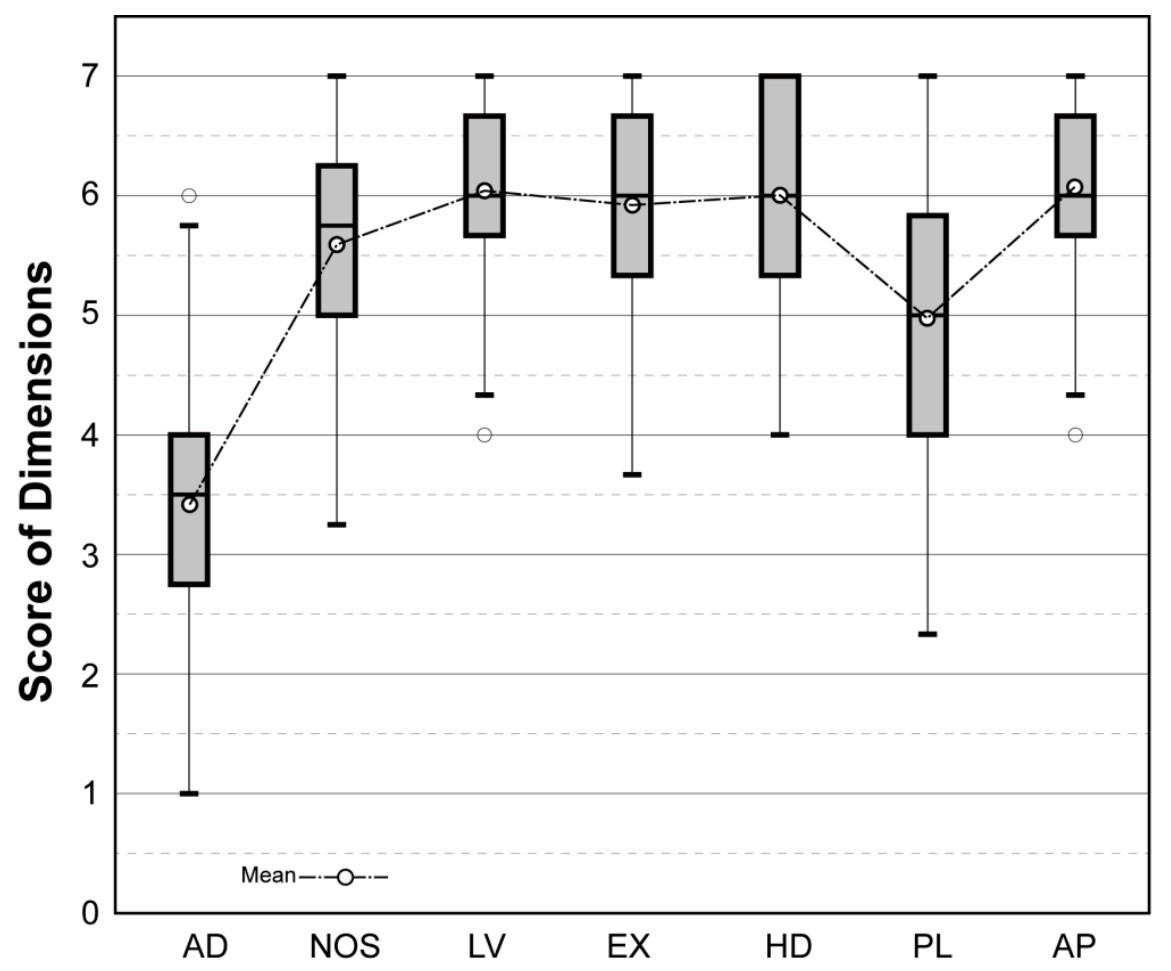

Figure 3. Boxplot of the proposed dimensions and their scores.

\subsection{Modeling and Regression}

Four dimensions (LV, EX, HD, and PL) were input as independent variables because they were statistically significant when individually tested in the regression model. To establish the best-fit model, the stepwise method was used. For each step, one additional dimension was entered into or removed from the model. In this way, the most significant predictors were gradually determined over several steps. The ANOVA test was applied to the model, and the F-value was used to indicate whether the linear relationship between the dependent variable and all of the predictors in the model could be inferred significantly as a whole.

The results indicated that Models $1(F=74.208, p<0.001), 2(F=66.319, p<0.001), 3(F=55.104$, $p<0.001)$, and $4(F=43.312, p<0.001)$ all significantly inferred a linear relationship between the dependent variable and the predictors. Among them, the $R^{2}$ of Model 4 was the largest $\left(R^{2}=0.587\right.$; see Table 6). The Durbin-Watson ( $D W)$ test was employed to ensure that the residuals of the regression were not correlated. If the Durbin-Watson index is equal or close to two, then we could be assured that the residuals were independent. The result suggested that the correlations among independent variables were not excessively biased parameter estimates of the multiple regression model $(D W=1.824)$. To further avoid multicollinearity among the independent variables, the criteria of the variance inflation factor $(V I F)<10$ and tolerance $>0.1$ must be met. The results of Model 4 suggest that the four-predictor was not multicollinear.

According to the results, the partial regression coefficients of the four dimensions were significant. The standardized coefficients were used to compare across the dimensions. The results showed that the PL estimate $(\beta=0.407)$ was the highest. $\operatorname{EX}(\beta=0.311)$ was the second and $\operatorname{HD}(\beta=0.226)$ was the third, whereas $\operatorname{LV}(\beta=0.133)$ was the least. Interestingly, the magnitude of PL was more than three times as much as LV. This result shows that the model predicted aesthetic pleasure well $\left(R^{2}=0.587\right)$, and it 
further supports the hypothesis that aesthetic pleasure is perceived as a multidimensional concept that embodies several major dimensions, which in turn affects aesthetic pleasure itself (Figure 4).

Table 6. Estimates of the regression models with the stepwise method.

\begin{tabular}{|c|c|c|c|c|c|c|c|c|c|c|c|}
\hline & & B & Beta & $\mathbf{t}$ & Sig. & $\begin{array}{l}\text { 95\% C.I. } \\
\text { (Lower) }\end{array}$ & $\begin{array}{l}\text { 95\% C.I. } \\
\text { (Upper) }\end{array}$ & Tolerance & VIF & $\mathbf{F}$ & Adjusted $\mathbf{R}^{2}$ \\
\hline \multirow{2}{*}{ Model-1 } & (Cons.) & 4.149 & & 17.956 & $* * *$ & 3.692 & 4.606 & & & \multirow[b]{2}{*}{$74.208^{* * *}$} & \multirow[b]{2}{*}{0.373} \\
\hline & PL & 0.392 & 0.610 & 8.614 & $* * *$ & 0.302 & 0.482 & 1.000 & 1.000 & & \\
\hline \multirow{3}{*}{ Model-2 } & (Cons.) & 2.329 & & 6.439 & $* * *$ & 1.613 & 3.045 & & & \multirow{3}{*}{$66.319 * * *$} & \multirow{3}{*}{0.517} \\
\hline & PL & 0.345 & 0.537 & 8.449 & $* * *$ & 0.264 & 0.425 & 0.964 & 1.037 & & \\
\hline & EX & 0.348 & 0.387 & 6.086 & $* * *$ & 0.235 & 0.461 & 0.964 & 1.037 & & \\
\hline \multirow{4}{*}{ Model-3 } & (Cons.) & 1.580 & & 4.068 & $* * *$ & 0.811 & 2.349 & & & \multirow{4}{*}{$55.104^{* * *}$} & \multirow{4}{*}{0.573} \\
\hline & PL & 0.280 & 0.437 & 6.735 & $* * *$ & 0.198 & 0.363 & 0.824 & 1.214 & & \\
\hline & EX & 0.284 & 0.316 & 5.046 & $* * *$ & 0.172 & 0.395 & 0.887 & 1.127 & & \\
\hline & HD & 0.241 & 0.273 & 4.038 & $* * *$ & 0.123 & 0.359 & 0.761 & 1.315 & & \\
\hline \multirow{5}{*}{ Model-4 } & (Cons.) & 1.145 & & 2.590 & * & 0.270 & 2.019 & & & \multirow{5}{*}{$43.312^{* * *}$} & \multirow{5}{*}{0.587} \\
\hline & PL & 0.261 & 0.407 & 6.184 & $* * *$ & 0.178 & 0.345 & 0.781 & 1.280 & & \\
\hline & EX & 0.280 & 0.311 & 5.038 & $* * *$ & 0.170 & 0.390 & 0.886 & 1.128 & & \\
\hline & HD & 0.200 & 0.226 & 3.200 & $* *$ & 0.076 & 0.323 & 0.678 & 1.476 & & \\
\hline & LV & 0.132 & 0.133 & 1.990 & * & 0.001 & 0.263 & 0.754 & 1.327 & & \\
\hline
\end{tabular}

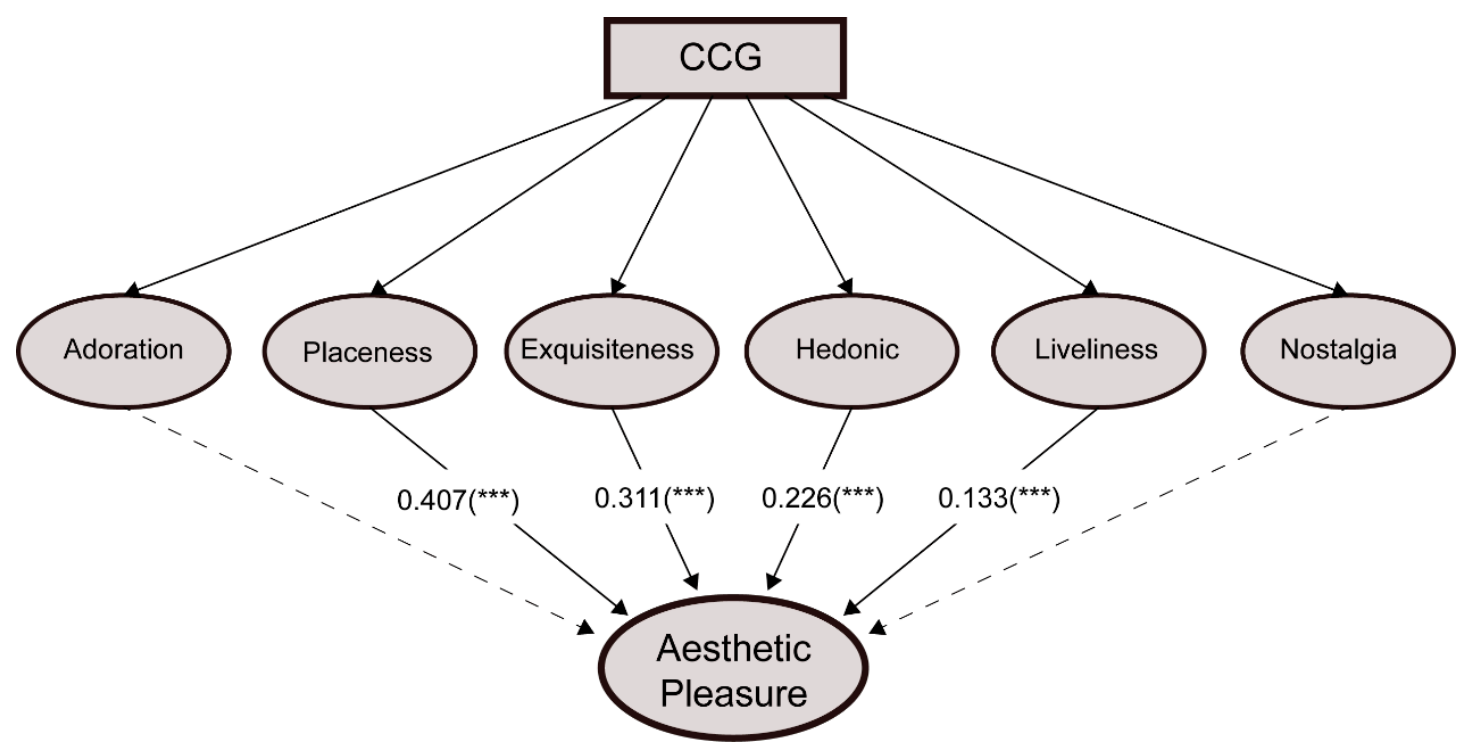

Figure 4. Model estimates of the proposed dimensions.

\section{Discussion}

Liveliness and exquisiteness primarily represent people's reactions to the visual aspects of the landscape environment on the material level, whereas hedonic value and placeness reflect people's reactions to the experiential aspects of the higher demands on the mental level. The current findings imply that the multidimensional characters of aesthetic pleasure are hierarchically linked. The results suggest that "placeness" is the most important dimension for the aesthetic appreciation of CCGs among the four selected dimensions. Stronger feelings of being attached to a place evoked higher levels of aesthetic appreciation. In the context of Chinese society, the attachment toward a CCG has been nourished through the enduring processes among didactical, social, cultural, psychological, and environmental interactions [52]. This result validates the argument that a sense of belonging and the feeling of rootedness inherited from previous generations might cause a certain degree of apriority to aesthetic appreciation [53]. The current findings are similar to Navin's study [54], which indicated that the yearning for a certain lifestyle is natural and can generate a biased preference in aesthetic appraisal, and the importance of "placeness" establishes effective bonds between people and the 
garden. For the future study of the aesthetics of CCGs, more attention should be paid to the concept of place, which seems to be a critical component not only because of its high influence but also because of its broad association with other perceived dimensions.

The dimension of exquisiteness plays a role similar to what Nasar referred to as "visual richness" [55] or "complexity" [19,56], both of which are reported for their contributions to increasing arousal during the appreciation process. The influence of exquisiteness to aesthetic pleasure might also be justified in other fields because this finding is consistent, with some studies showing that moderate-to-high levels of complexity in a scene contribute to increased aesthetic appraisal $[15,16,57]$. Exquisiteness reflects the overall design quality of a CCG, which is often constrained by its small size given that most were built in the old city center [58]. Within this limited space, the humanmade environment is deliberately shaped with small buildings, galleries, pavilions, and terraces to fit natural elements such as trees, vegetation, water, and stones, creating scenery layers with visual richness (Figure 5). These landscape elements are ingeniously decorated with carefully designed details such as windows, grills, screens, railings, and walls, which increase the sense of exquisiteness in the garden. On the other hand, the hedonic tone of feelings strengthens the aesthetic value of a CCG, as is implied through the design strategies that respond to people's physiological needs by providing comfortable and convenient recreational facilities such as green shade, corridors, pathways, stools, and backrests. These landscape elements (e.g., curved bridges, rockery works, caves, and courtyards) are connected into a series of views (Figure 5) that translate into the space montage of so-called "varying sceneries with changing view-points $[59,60]$. In this way, the temporal and spatial dimension is extended when people slowly wander into the garden for relaxation [61]. Coincidently, our findings echo the literati's intention of building such a garden because they intended to keep a distance from the chaotic society at that time and created a peaceful living place with spiritual freedom beyond the limits of immediate reality [6]. According to the results, we revealed the consistency between the design intention and the actual effect of the experience in the garden [20].

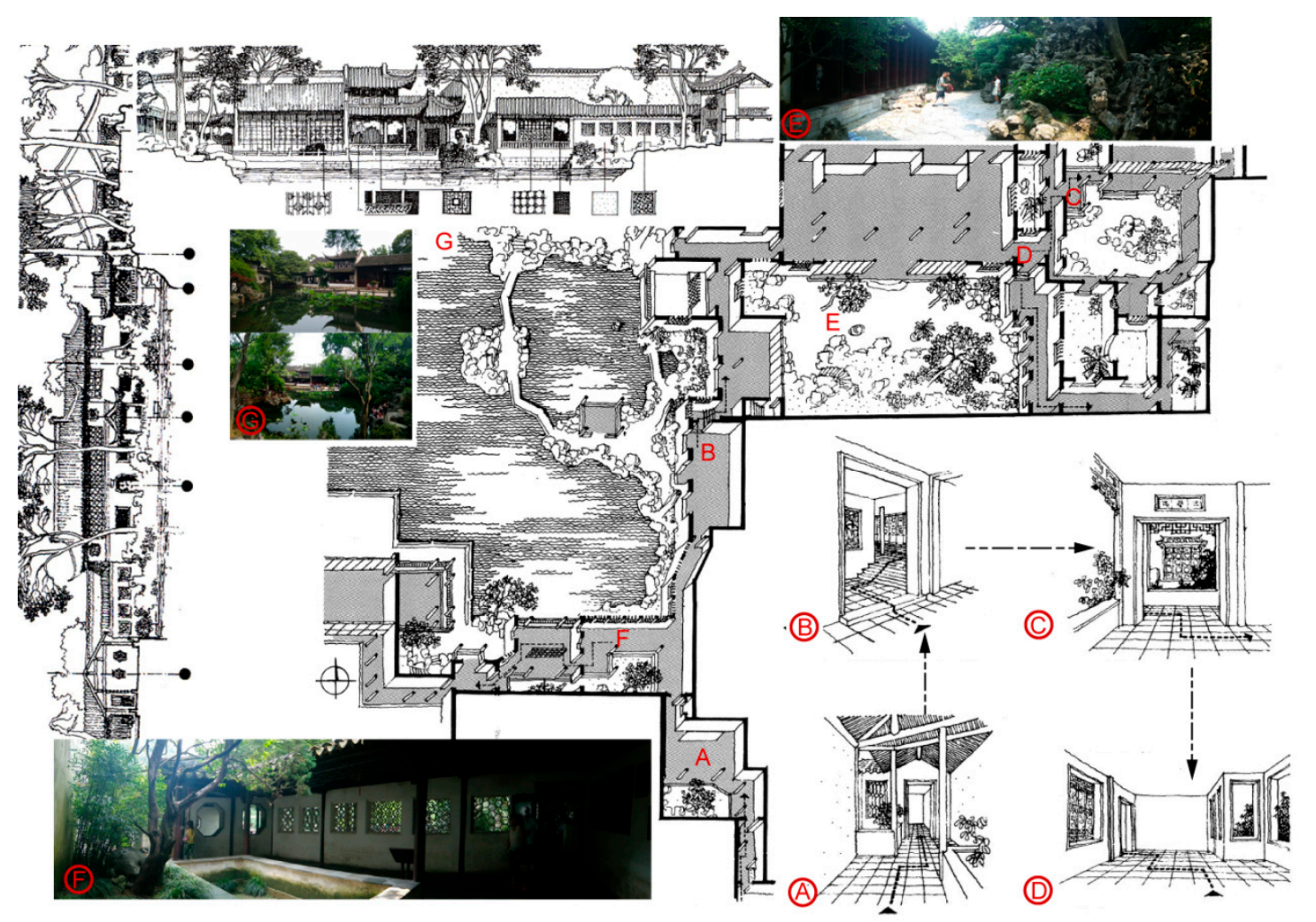

Figure 5. Illustrations of the varying sceneries with changing viewpoints. 
Thus far, the literature has discussed the organic nature or naturalness $[19,44,62]$ which encapsulates the notion of "liveliness", which Alexander (2002) highlighted to explain the unique quality of inhering both the natural and humanmade environments and even throughout the universe [63]. Although the result showed that liveliness significantly influences aesthetic pleasure, as is consistent with Sevenant's study [28], it only exerts a subordinate contribution to aesthetic pleasure compared with the other three dimensions. As the perception of liveliness transcends our daily experience, we might use it without conscious awareness. Or maybe liveliness is of a higher level of perception that could emerge only when basic dimensions such as placeness and hedonic value are fulfilled. Furthermore, because the results showed a significant correlation between liveliness and the other three described dimensions, liveliness might indirectly affect aesthetic pleasure through the mediating effect of the other dimensions. Regardless, these interesting hypotheses are beyond the scope of the current paper and should be examined in future studies.

\section{Conclusions}

Investigating how people perceive CCGs and what causes them pleasing are continuously important issues for landscape designers and environmental psychologists. This research originates from the hypothesis that the aesthetic pleasure of a CCG is multidimensional. By taking the Liu-Yuan Garden as a case study, we present how a measurement instrument was developed to investigate the perceived dimensions of landscape appreciation. Through analysis, six correlated yet distinct dimensions-“Adoration", "Nostalgia", "Liveliness", "Exquisiteness", "Hedonic Value", and "Placeness" - were eventually extracted and validated; four of them were correlated with aesthetic pleasure. Among these dimensions, "Liveliness" and "Exquisiteness" were the two that represented people's reactions to the humanmade/natural environment of CCGs on the material level, whereas "Hedonic Value" and "Placeness" reflect people's mental demands. The results indicated that "Placeness" most influences aesthetic pleasure; "Exquisiteness" and "Hedonic Value" rank in the middle; and "Liveliness" is least influential. These findings imply that people have hierarchical psychological activities and emotions when they experience CCGs. As a result, we also revealed the consistency between the original design intention and the actual experience of the garden. As a "humanized nature", a CCG is a dialectical unity of form and content, indicating a subjective consciousness that originates from the Chinese philosophy of "achieving harmony between heaven and human" in the aesthetic appreciation process [57], because CCGs are usually regarded as an idealized world that reflects a gardener's outlook on life, preferences, and perceptions and cognitions of the external world.

\section{Limitations}

This explorative work attempted to contribute to the landscape aesthetic theory. More work is pending to provide additional support to the initial findings from different perspectives, diminish possible limitations, and facilitate other researchers to produce more generalized discoveries in the future. In this explorative study, we aimed to infer the attitudes of the young population by investigating universities students. For the future study, the sample size should be enlarged to other populations. Also, as behavior and attitude attributes are more significant determinants of aesthetic preference compared with the socio-demographic characteristics (Sevenant and Antrop, 2009), some control variables (e.g., education, social status, region, culture, and background) were purposely put aside because we sought to explore potential psychological structure in this pilot study for inspiration; however, more works should be carried on to investigate and validate these confounds to have more precise results. It might also be helpful to include other variables to increase the explanatory power of the proposed model. Furthermore, additional gardens of different types should be tested for comparison to examine the initial findings in a broader sense. Lastly, this research might contribute to our knowledge in the field of landscape studies, inspire better comprehension of the study of CCGs, and stimulate ideas for corresponding design practice. 
Author Contributions: Conceptualization, X.L. (Xin Li) and B.X.; Data curation, X.L. (Xing Liu); Formal analysis, A.L.; Investigation, X.L. (Xing Liu) and N.L.; Methodology, X.L. (Xin Li); Project administration, B.X.; Resources, X.L. (Xing Liu) and N.L.; Validation, N.L.; Writing—original draft, X.L. (Xin Li); Writing—review \& editing, B.X. and A.L.

Funding: This research was funded by National Natural Science Foundation of China (No. 51408442) and Hubei Provincial Natural Science Foundation of China (No. 2018CFB570).

Conflicts of Interest: The authors declare no conflict of interest.

\section{References}

1. Nasar, J.L. The effect of sign complexity and coherence on the perceived quality of retail scenes. J. Am. Plan. Assoc. 1988, 53, 499-509. [CrossRef]

2. Nasar, J.L.; Julian, D.; Buchman, S.; Humphreys, D.; Mrohaly, M. The emotional quality of scenes and observation points: A look at prospect and refuge. Landsc. Plan. 1988, 10, 355-361. [CrossRef]

3. Nasar, J.L.; Hong, X. Visual preferences in urban signscapes. Environ. Behav. 1999, 31, 671-691. [CrossRef]

4. Mastandrea, S.; Bartoli, G.; Carrus, G. The automatic aesthetic evaluation of different art and architectural styles. Psychol. Aesthet. Creat. Arts 2011, 5, 126-134. [CrossRef]

5. López-Rodríguez, A.; Escribano-Bombín, R.; Hernández-Jiménez, V.; Bell, S. Perceptions of ecological and aesthetic quality by natural resource professionals and local people. a qualitative exploration in a mountainous landscape (La Rioja, Spain). Landsc. Res. 2018. [CrossRef]

6. Han, C. The aesthetics of wandering in the Chinese literati garden. Stud. Hist. Gard. Des. Landsc. 2012, 32, 297-301. [CrossRef]

7. Cameron, C. UNESCO and Cultural Heritage; A Companion to Heritage Studies; John Wiley \& Sons, Inc.: Hoboken, NJ, USA, 2015.

8. Nasar, J.L. Urban design aesthetics: The evaluative qualities of building exteriors. Environ. Behav. 1994, 26, 377-401. [CrossRef]

9. Yılmaz, S.; Özgüner, H.; Mumcu, S. An aesthetic approach to planting design in urban parks and greenspaces. Landsc. Res. 2018, 43, 965-983. [CrossRef]

10. Lang, J. Symbolic aesthetic in architecture: Toward a research agenda. In Environmental Aesthetics: Theory, Research, and Applications; Nasar, J.L., Ed.; Cambridge University Press: New York, NY, USA, 1988; pp. 11-26.

11. Lang, J. Urban Design: The American Experience; Wiley: New York, NY, USA, 1994.

12. Bishop, I.D.; Ye, W.S.; Karadaglis, C. Experiential approaches to perception response in virtual worlds. Landsc. Urban Plan. 2001, 54, 115-123. [CrossRef]

13. Daniel, T.C. Whither scenic beauty? Visual landscape quality assessment in the 21st century. Landsc. Urban Plan. 2001, 54, 267-281. [CrossRef]

14. Val, G.F.; Atauri, J.A.; Luci, J.V. Relationship between landscape visual attributes and spatial pattern indices: A test study in Mediterranean-climate landscapes. Landsc. Urban Plan. 2006, 77, 393-407. [CrossRef]

15. Kaplan, S. Perception and landscape: Conceptions and misconceptions. In Environmental Aesthetics: Theory, Research, and Applications; Nasar, J.L., Ed.; Cambridge University Press: Cambridge, UK; New York, NY, USA, 1988.

16. Ulrich, R.S. Human responses to vegetation and landscapes. Landsc. Urban Plan. 1986, 13, 29-44. [CrossRef]

17. Lothian, A. Landscape and the philosophy of aesthetics: Is landscape quality inherent in the landscape or in the eye of the beholder? Landsc. Urban Plan. 1999, 44, 177-198. [CrossRef]

18. Lothian, A. Visual impact assessment of some developments in South Australia. Aust. Plan. 2008, 45, 35-41. [CrossRef]

19. Ode, Å.; Tveit, M.; Fry, G. Capturing landscape visual character using indicators: Touching base with landscape aesthetic theory. Landsc. Res. 2008, 33, 89-117. [CrossRef]

20. Lu, A.D. Lost in translation: Modernist interpretation of the Chinese garden as experiential space and its assumptions. J. Archit. 2011, 16, 499-527. [CrossRef]

21. Wang, H.; Herr, C. Measuring the Perceptive Intricacy of the Chinese Scholar Garden. In Proceedings of the 22nd CAADRIA Conference, Xi'an Jiaotong-Liverpool University, Suzhou, China, 5-8 April 2017; pp. 335-344. 
22. Ostwald, M.J. The mathematics of spatial configuration: Revisiting, revising and critiquing justified plan graph theory. Nexus Netw. J. 2011, 13, 445-470. [CrossRef]

23. Ostwald, M.J. Examining the relationship between topology and geometry: A configurational analysis of the rural houses (1984-2005) of Glenn Murcutt. J. Space Syntax 2011, 2, 223-246.

24. Costall, A.P. Are theories of perception necessary? A review of Gibson's the ecological approach to visual perception. J. Exp. Anal. Behav. 1984, 41, 109-115. [CrossRef] [PubMed]

25. Tu, Y. Analyzing the visual records of a Chinese ash at the Liu Yuan in the modern times. Archit. J. 2016, 1, 24-30.

26. Yu, R.; Gu, N.; Ostwald, M.J. Transparency or mystery: Using syntactical data to visualize the properties of the Traditional Chinese Private Garden. Vis. Eng. 2016, 4, 1-9. [CrossRef]

27. Council of Europe. Official Text of the European Landscape Convention. 2000. Available online: http://www.coe.int/t/e/Cultural_Co-operation/Environment/Landscape/ (accessed on 12 January 2015).

28. Sevenant, M.; Antrop, M. The use of latent classes to identify individual differences in the importance of landscape dimensions for aesthetic preference. Land Use Policy 2010, 27, 827-842. [CrossRef]

29. Zaidel, D.W.; Nadal, M.; Flexas, A.; Munar, E. An evolutionary approach to art and aesthetic experience. Psychol. Aesthet. Creat. Arts 2013, 7, 100-109. [CrossRef]

30. Hassenzahl, M.; Tractinsky, N. User experience-A research agenda. Behav. Inf. Technol. 2006, $25,91-97$. [CrossRef]

31. Morgan, R. Some factors affecting coastal landscape aesthetic quality assessment. Landsc. Res. 1999, 24, 167-184. [CrossRef]

32. Feagin, S.; Maynard, P. Aesthetics; Oxford University Press: Oxford, UK, 1997.

33. Dutton, D. The Art Instinct; Oxford University Press: New York, NY, USA, 2009.

34. Hekkert, P. What I talk about when I talk about aesthetics. In Proceedings of the 23rd Biennial Congress of the International Association of Empirical Aesthetics; Kozbelt, A., Ed.; Cambridge University Press: New York, NY, USA, 2014; pp. 244-246.

35. Da Silva, O.; Crilly, N.; Hekkert, P. How people's appreciation of products is affected by their knowledge of the designers' intentions. Int. J. Des. 2015, 9, 21-33.

36. Gobster, P.H.; Nassauer, J.I.; Daniel, T.C.; Fry, G. The shared landscape: What does aesthetics have to do with ecology? Landsc. Ecol. 2007, 22, 959-972. [CrossRef]

37. Berleant, A. Aesthetic perception in environmental design. In Environmental Aesthetics: Theory, Research, and Applications; Nasar, J.L., Ed.; Cambridge University Press: New York, NY, USA, 1988; pp. 84-97.

38. Purcell, T.; Peron, E.; Berto, R. Why do preferences differ between scene types? Environ. Behav. 1998, 33, 93-106. [CrossRef]

39. Cheng, A.S.; Kruger, L.E.; Daniels, S.E. "Place" as an integrating concept in natural resource politics: Propositions for a social science research agenda. Soc. Nat. Resour. 2003, 16, 87-104. [CrossRef]

40. Van den Berg, A.E.; Vlek, C.A.J.; Coeterier, J.F. Group differences in the aesthetic evaluation of nature development plans: A multilevel approach. J. Environ. Psychol. 1998, 18, 141-157. [CrossRef]

41. Augustin, M.D.; Wagemans, J.; Carbon, C.C. All is beautiful? generality vs. specificity of word usage in visual aesthetics. Acta Psychol. 2012, 139, 187-201. [CrossRef] [PubMed]

42. Lavie, T.; Tractinsky, N. Assessing dimensions of perceived visual aesthetics of web sites. Int. J. Hum. -Comput. Stud. 2004, 60, 269-298. [CrossRef]

43. Hassenzahl, M.; Monk, A. The inference of perceived usability from beauty. Hum. -Comput. Interact. 2010, 25, 235-260. [CrossRef]

44. Tveit, M.; Ode, Å.; Fry, G. Key concepts in a framework for analysing visual landscape character. Landsc. Res. 2006, 31, 229-255. [CrossRef]

45. Hartig, T.; Evans, G.W.; Jamner, L.D.; Davis, D.S.; Gärling, T. Tracking restoration in natural and urban field settings. J. Environ. Psychol. 2003, 23, 109-123. [CrossRef]

46. Hair, J.F.; Black, W.C.; Babin, B.J. Multivariate Data Analysis: A Global Perspective, 7th ed.; Pearson Education International: Upper Saddle River, NJ, USA, 2010.

47. Lee, R.; Lockshin, L. Reverse country of origin effects of product perceptions on destination image. J. Travel Res. 2012, 51, 502-511. [CrossRef] 
48. Gerbing, D.W.; Hamilton, J.G. Viability of exploratory factor analysis as a precursor to confirmatory factor analysis. Soc. Sci. Electron. Publ. 1996, 3, 62-72. [CrossRef]

49. Fabrigar, L.R.; Wegener, D.T.; MacCallum, R.C.; Strahan, E.J. Evaluating the use of exploratory factor analysis in psychological research. Psychol. Methods 1999, 4, 272-299. [CrossRef]

50. Blijlevens, J.; Thurgood, C.; Hekkert, P.; Chen, L.L.; Leder, H.; Whitfield, T.W.A. The aesthetic pleasure in design scale: The development of a scale to measure aesthetic pleasure for designed artifacts. Psychol. Aesthet. Creat. Arts 2017, 11, 86-98. [CrossRef]

51. Fornell, C.; Larcker, D.F. Evaluating structural equation models with unobservable variables and measurement error. J. Mark. Res. 1981, 18, 39-50. [CrossRef]

52. Jones, P.B.; Woudstra, J. Social order versus 'natural' disorder in the Chinese garden. Stud. Hist. Gard. Des. Landsc. 2014, 34, 151-175. [CrossRef]

53. Carlson, A. On the aesthetic appreciation of Japanese gardens. Br. J. Aesthet. 1997, 37, 47-56. [CrossRef]

54. Navin, T. The venetian city garden: Place, typology, and perception. J. Archit. Educ. 2010, 63, 178-179. [CrossRef]

55. Nasar, J.L. Perception and evaluation of residential street scenes. In Environmental Aesthetics: Theory, Research, and Applications; Nasar, J.L., Ed.; Cambridge University Press: Cambridge, UK, 1988.

56. Arnheim, R. Order and complexity in landscape design. In Toward a Psychology of Art; Arnheim, R., Ed.; University of California Press: Berkeley, CA, USA, 1966.

57. Junge, X.; Lindemann-Matthies, P.; Hunziker, M.; Schüpbach, B. Aesthetic preferences of non-farmers and farmers for different land-use types and proportions of ecological compensation areas in the Swiss lowlands. Biol. Conserv. 2011, 144, 1430-1440. [CrossRef]

58. Fung, S. The interdisciplinary prospects of reading Yuan Ye. Stud. Hist. Gard. Des. Landsc. 1998, 18, $211-231$. [CrossRef]

59. Peng, Y.G. Analysis of the Traditional Chinese Garden; China Architecture \& Building Press: Beijing, China, 1986.

60. Chen, D.; Meng, F. The points in the infinite dimensional space: The analysis on the space meaning of varying sceneries with changing view-points, lingering garden (Liu Yuan) as an example. Huazhong Archit. 2009, 27, 173-177.

61. Lu, S. Hidden orders in Chinese gardens: Irregular fractal structure and its generative rules. Environ. Plan. B 2010, 37, 1076-1094. [CrossRef]

62. Henderson, R. The Gardens of Suzhou; University of Pennsylvania Press: Philadelphia, PA, USA, 2013.

63. Alexander, C. The Nature of Order: An Essay on the Art of Building and the Nature of the Universe; Center for Environmental Structure: Berkeley, CA, USA, 2002. 